\title{
EDUCAÇÃO, ÉTICA E DEMOCRACIA: DIVERSOS OLHARES SOBRE O TEMA
}

COELHO, Juliane Maria Pereira ${ }^{1}$

COLVARA, Jonas Santos ${ }^{2}$

ROLIM, Sandra Catarina ${ }^{3}$

COELHO, Juliane Maria Pereira; COLVARA, Jonas Santos; ROLIM, Sandra Catarina. Educação, Ética e Democracia: Diversos Olhares Sobre o Tema. Revista Científica Multidisciplinar Núcleo do Conhecimento. Edição 04. Ano 02, Vol. 01. pp 179-190, Julho de 2017. ISSN:2448-0959

\section{RESUMO}

Este é um trabalho desenvolvido para a disciplina de Ética, Educação e Democracia. Através de pesquisas bibliográficas busca-se realizar um apanhado de ideias, desenvolvidas e trabalhadas durante os anos, e tomar posse desses elementos conceituais e suas possíveis influências no pensamento moderno a respeito do tema levantado. Demonstrar as influências filosóficas, psicológicas educacionais que perpassam do passado ao presente e de que maneira essas influências modificaram conceitos e impactaram na contemporaneidade do tema. Ética, Educação e Democracia são o alicerce do pensamento e das ações que irão promover o desenvolvimento do ser humano integral, utilizador das ferramentas do conhecimento e de suas ações na implementação de valores de cidadania, de comunidade e de inovação social.

Palavras-chaves: Ética, Educação, Democracia.

\footnotetext{
${ }^{1}$ Mestranda em Ciências da Educação na Universidad e la Empresa- Uruguai.

${ }^{2}$ Mestrando em Ciências da Educação na Universidad e la Empresa- Uruguai.

${ }^{3}$ Mestranda em Ciências da Educação na Universidad e la Empresa- Uruguai.
} 


\section{INTRODUÇÃO}

Esse é um estudo em que se busca, através da pesquisa no referencial bibliográfico, o entendimento sobre como pensadores durante os anos de 2014 e 2015 desenvolveram conceitos contemporâneos a respeito das questões sobre como a ética, a educação e a democracia influenciam e foram influenciados por outros autores e suas implicações no pensamento moderno.

Temos a intenção de demonstrar as novas teorias e fundamentos da moderna conceituação sobre Ética, Educação e Democracia e sua contemporaneidade no contexto educacional e na formação do cidadão.

\section{DESENVOLVIMENTO}

Vivemos numa época em que as transformações sociais, relacionadas à Ética, Educação e Processos Democráticos passa por momentos de reorganização à partir dos sujeitos a quem uma série de conceitos colocados no passado já não suportam as mudanças de pensamento e a mudança no agir da moderna sociedade.

Levantamos aqui algumas ideias como as de Boaventura de Sousa Santos, (2002/2004), Enrique Dussel (2000) e Paulo Freire (2000/2002) entre outros, que afirmam ser necessário o surgimento de um novo paradigma científico que valorize as diferenças entre os indivíduos e que esteja baseado em princípios éticos de justiça e igualdade, tentando superar o quadro de opressão social em que muitos vivem atualmente.

Temos um modelo de pensamento racional científico, utilizado durante anos considerado por seus responsáveis como a maneira ideal, senão a única de chegarmos a verdadeira iluminação a respeito das coisas do mundo.

Segundo Santos (1997), a construção desse modelo de racionalidade ocorreu através de inúmeras contribuições de filósofos, físicos, matemáticos e demais pensadores das Ciências Naturais que buscavam entender o mundo a partir de uma explicação baseada na razão e na matematização das coisas. O objetivo principal era estabelecer 
relações sistemáticas entre os objetos estudados a partir de análises matemáticas, os únicos considerados racionais.

Vários outros pensadores vieram a confirmar tais ideias baseados nesse pensamento científico que dominava a época descrevendo como a única aceitação para o pensamento científico, a saber:

O meu livro pode esperar muitos séculos pelo seu leitor. Mas mesmo Deus teve de esperar seis mil anos por aqueles que pudessem contemplar seu trabalho. (KEPLER, 1939, apud SANTOS, 1997, p.15)

(...) não deixo de receber uma extrema satisfação com o progresso que julgo ter feito em busca da verdade [...] se entre as ocupações dos homens, puramente homens, alguma há que seja solidamente boa e importante, ouso crer que é aquela que escolhi. (DESCARTES, 1984, apud SANTOS, 1997, p. 15)

À medida que o tempo passa e que novos filósofos e estudiosos não só das Ciências Sociais começam a abordar um diferente paradigma referente as essas ideias aparece em destaque a importância dessa processo do pensamento ético, educacionais e democráticos, na educação, para que se possa libertar o indivíduo, até então um oprimido social e nas ações do pensar, tornando-o um ser cidadão e livre para opinar e reforçar a sua construção do conhecimento , tornar-se crítico em sua visão social, poder questionar e opinar sobre tudo que influência direta ou indiretamente sua vida. $\mathrm{E}$, ao mesmo tempo, afirmar e valorizar o processo educativo, quando compreendido a partir das relações estabelecidas entre os sujeitos uns com os outros e com o mundo, como sendo responsável pelo desenvolvimento de saberes essenciais para a construção de um novo paradigma científico que defenda a justiça, a igualdade e a ética como princípios básicos da vida.

Pensando primeiramente em ética na construção dessa nova visão temos Dussel, (2000), que diz, o princípio ético se constitui em três momentos: o primeiro é o da produção humana, o segundo é de reprodução da vida nas instituições e valores culturais, e por fim, o terceiro momento se refere ao desenvolvimento dessa vida em 
tais instituições. Assim, a ética se caracteriza por ser um princípio de vida fundado em uma exigência de responsabilidade com o dever de viver, produzir e reproduzir.

Já para Freire, (2011), o homem é uma criatura que não apenas vive, mas, sobretudo, existe na relação com os outros homens. De forma ética a consciência da existência significa a capacidade de discernir as suas relações, destacando-se o papel da criticidade na comunicação ou diálogo com o outro. Freire ressalta como característica da natureza humana esta capacidade de discernimento, de busca do conhecimento para sua humanização, que consiste na vocação ontológica do homem. Para ele:

É por estarmos sendo este ser em permanente procura, curioso, tomando distância de si mesmo e da vida que porta; é por estarmos sendo este ser dado à aventura e à paixão de conhecer [...] é por estarmos sendo assim que vimos nos vocacionando para a humanização e que temos na desumanização, fato concreto na história, a distorção da vocação. (FREIRE, 2011, p. 99).

De modo semelhante, Santos, (2000), afirma que a ética que deverá surgir no novo paradigma está fundamentada no princípio da solidariedade a partir do momento que nos tornamos responsáveis pela existência futura do outro. Segundo o autor "a nova ética não é antropocêntrica, nem individualista, nem busca apenas a responsabilidade das consequências imediatas. É uma responsabilidade pelo futuro".

Todo esse processo educativo passa a ser entendido como "a libertação", de um pensamento arbitrário que deixa de considerar, chegando mesmo a discriminar aqueles que não possuem um destaque social. A educação como emancipação individual e social passa a ser um dos pressupostos exigidos para a elaboração de uma nova ética que de fato liberte os oprimidos.

Segundo Freire (1987), "é preciso que os que assim se encontram negados no direito primordial de dizer a palavra reconquistem esse direito, proibindo que esse assalto desumanizante continue". Assim, a educação, com base na pedagogia freiriana, é tida como uma ação libertadora que reconhece a existência dos oprimidos e a torna objeto 
de reflexão e crítica transformadoras da realidade acrescida de uma ética e democratização libertadoras.

O exercício da cidadania é analisado por Brochado, (2010), em sua palestra intitulada "Ética e as relações entre estado, política e cidadania". Na oportunidade, a autora traz do Dicionário Aurélio o conceito de cidadão sendo "aquele indivíduo no gozo de direitos civis e políticos de um Estado; é um indivíduo na função dos seus direitos ou no desempenho dos seus deveres para com o Estado" para questionar, em sua exposição, a formação que se faz necessária ao cidadão para realizar reivindicações políticas afirmando que "cidadãos em maioria desconhecem o histórico e o contexto atual de seus próprios direitos fundamentais; não reconhecem o valor da conquista de uma Constituição democrática, o significado de republica." Juntam-se a essas definições sobre afirmações de liberdade, cidadania, participação na comunidade todas essas ações implementadas pela Educação, pela Ética, e pela Democracia com suas características libertadoras.

Segundo Albuquerque, (2006), a construção de uma nova ética faz a exigência de um diálogo problematizador - crítico a ser promovido pela educação.

Esse diálogo é que gera e faz nascer um humano crítico, ou seja, os homens surgem através de seus atos, de suas palavras, de suas ações, autênticas, verdadeiras que podem transformar o mundo que nesse ciclo significa a transformação do próprio homem.

Ressaltamos, aqui que Freire, (2000), desenvolve o conceito de democracia intimamente ligado à prática da reflexão e diálogo capaz de modificar a consciência e o comportamento humano, constituindo-se como pressuposto da vida social e política. A democracia está também inacabada e, como tal, o seu "ser mais" depende da criticidade. Esta é a formulação freiriana de democracia:

A democracia que, antes de ser forma política, é forma de vida, se caracteriza, sobretudo por forte dose de transitividade de consciência no comportamento do homem. Transitividade que não nasce e nem se desenvolve a não ser dentro de certas 
condições em que o homem seja lançado ao debate, ao exame de seus problemas e dos problemas comuns. Em que o homem participe. (Freire, 2000).

A denominada independência ética do indivíduo está diretamente ligada à noção de consciência crítica e liberdade de pensamento, uma vez que no Estado Democrático de Direito o indivíduo racional possui liberdade e direito de participação nas decisões da máquina pública. Portanto, visando reequilibrar qualquer desarmonia e com o intuito assegurar a igualdade e liberdade de pensamento do indivíduo em conformidade com os fundamentos éticos da razão, são estabelecidos os direitos à cidadania.

Segundo Freire (2011), "[...] pronunciando o mundo, os homens o transformam, o diálogo se impõe como caminho pelo qual os homens ganham significação enquanto homens". O que deveria estar contido na concepção dos educadores, ao pensar na educação, é que ela seja democrática e ao mesmo tempo traga a realidade vivida pelos alunos e dela se possa extrair conhecimentos significativos, que propiciassem a aquisição de uma consciência que modifica o entorno sem querer mudar o sujeito, ou seja, conhecer outras culturas em que os novos conhecimentos são pertinentes e necessários. Para isso, nada melhor que sair da experiência de cada um e construir o novo.

Temos ainda em Vieira De Mello, (2001), a afirmação que, procurar confrontar o pensamento ético, voltado para perscrutar a liberdade íntima e moral do homem é analisar a conduta ética, dirigida para os valores superiores, com o pensamento científico-tecnológico do "homem curioso", inclinado à compreensão do mundo exterior, implícita ou explicitamente para dominá-lo.

Notadamente a consciência de autonomia e libertação é de alguma forma custosa ao homem. Segundo Kant, (2002), aprendemos que a situação de menoridade quando alguém se encontra dependente de terceiros para deliberar sobre suas causas, é mais confortável do que situações em que se deve fazer uso da própria razão, exercer o seu direito. Alargar as fronteiras do conhecimento do mundo e de si mesmo exige esforço e responsabilidade. 
Se existe uma necessidade avassaladora de se ensinar ética, educação e cultura que deveriam ser valores inatos aos seres humanos é porque existe uma lacuna de aprendizagem desses conceitos desde tenra idade até a maturação do indivíduo. Ciente de que esses valores levam a condutas libertadoras concluímos que liberdade é uma tarefa difícil, árdua em sua busca.

E se todos esses conceitos existem mais necessitam serem ensinados esse papel está delegado à escola. Segundo Dewey,(1997), é preciso observar que é a escola que mais detém o pensador em suas incursões apesar de não ser a única, por essa razão devemos pensar em como uma sociedade cuida da manutenção e expansão da democracia se as instituições que a compõe pautam-se constantemente em ações não democráticas?

A importância da educação escolar, na formação do homem tem sido destacada por diferentes autores no curso do pensamento ocidental, contudo a visão de que os processos educativos se voltam para sujeitos cujas identidades precisam ser consideradas, nem sempre é algo de fácil aceitação.

É preciso incluir a escola na vida das pessoas e, sobretudo, as pessoas no cotidiano da escola, inserir as experiências sócio - simbólicas na educação, interligando-a de forma viva, democrática e cidadã a um projeto ético-político-epistemológico mais ampliado.

Para Oliveira, (2008), o exercício da cidadania plena perpassa pela discussão sobre os saberes, que não mais devem ser vislumbrados como mero produto, mas como contexto, visão de mundo, palavra plural. A "cultura da conversa", as aprendizagens experimentadas na comunidade, no partido político, ou na família, compõem o homem e esses saberes devem ser considerados tanto quanto os saberes "oficiais" da escola. Esta é uma questão fundamentalmente política e necessária para que possamos redimensionar a educação, interligando-a a todos os campos da experiência social, simbólica e cultural. 
Nesse sentido, segundo Carvalho, (2016), a educação ética não é uma tarefa de especialistas, mas de toda a comunidade, não é fruto de um esforço isolado, mas de uma ação conjunta e contínua de todo o entorno social.

O trabalho educacional escolar passa pelo ensino de disciplinas específicas, mas está longe de ter sua terminalidade. Não podemos torná-lo, nas atuais condições históricas, como resultante de uma relação pessoal isolada ou como se cada professor fosse um "preceptor" isolado em sua relação pessoal com os alunos e a escola uma simples somatória dessas relações individualizadas. A escola é regida por uma série de valores, práticas e objetivos institucionais decorrentes da peculiaridade de sua história e de sua tarefa social de iniciação dos jovens no mundo do conhecimento, da ética e da democracia.

O sucesso ou não, na tarefa de mostrar aos jovens essas questões do mundo dos valores e princípios éticos depende de todo um conjunto na qual os atores sociais, além de suas funções específicas, tornam-se um amparo, comprometendo-se em transmitir uma série de valores que se traduzem em responsabilidades e atitudes educativas próprias ao mundo escolar.

Como ressalta Arendt, (1978), o educador está aqui em relação ao jovem como representante de um mundo pelo qual deve assumir responsabilidade e, embora não o tenha feito e ainda que secreta ou abertamente possa querer que ele fosse diferente do que é. Essa responsabilidade não é imposta arbitrariamente aos educadores; ela está implícita no fato de que os jovens são introduzidos por adultos em um mundo em contínua mudança. E essa não é uma responsabilidade individual.

Ao remeter a Freire, (1996), entendemos que "[...] o espaço pedagógico é um texto para ser constantemente 'lido', 'interpretado', 'escrito' e 'reescrito'. Neste sentido, quanto mais solidariedade exista entre o educador e o educando no "trato" desse espaço, tanto mais possibilidades de aprendizagem democrática se abrem na escola". Assim, é imprescindível entender os vários fatores que influenciarão, através da educação enquanto intervenção, nas questões presentes no mundo, que atendam à diversidade e tantas outras tecnologias afeitas à globalização. 
O tipo de pessoa que somos e o que pensamos de nós mesmos são definidos pela forma social, educativa e ética na qual estamos inseridos.

A reconstrução da identidade coletiva se dá, sobretudo, com a transformação dessa forma socioeconômica.

Diante do exposto é impensável separar educação e ética. Todos os processos para implementar ações nos processos educacionais passam pelos valores éticos.

O filósofo e educador Freire, (2008), em Pedagogia da Autonomia, desenvolve as relações entre educação e ética, afirmando que "não é possível pensar os seres humanos longe, sequer, da ética, quanto mais fora dela. Estar longe, ou pior, fora da ética, entre nós, mulheres e homens, é uma transgressão". E ainda explicita a relação ética e educação como condição fundamental do querer ser mais, do tornar-se humano mediante uma prática "fundamentalmente justa e ética contra a exploração dos homens e das mulheres e em favor de sua vocação de querer ser mais"

Educar é senão o processo que vem a caracterizar a humanidade de cada um. O homem necessita construir-se, através de si mesmo e também sob a influência do outro (o estado, a política, a mídia, os processos educacionais). Isso o leva a acharse e colocar-se no mundo através da ética, da educação e da democracia.

No tocante a educação a tarefa principal, seu desafio, sua responsabilidade vai de encontro direto aos conceitos de ética, demonstrando a necessidade de garanti-la para a humanidade. É essa a tarefa que cabe à educação se realmente quiser superar a dicotomia entre o discurso eloquente e estatístico sobre os avanços na educação, mas que, na prática, reforça a tese do aniquilamento do indivíduo para atender a demanda do mercado e a realidade efetiva que aponta a precariedade da educação.

\section{CONSIDERAÇÕES FINAIS}

Quando nos referimos ao ato educativo como o de formar indivíduos para o mundo social instituímos a participação de valores como Ética, Democracia e Educação em 
seu fim. E esse parâmetro pode ser expresso em um outro discurso paralelo e a ele correspondente: o de formar os indivíduos para o exercício da Cidadania.

A educação cumpre esse papel fornecendo aos estudantes diversas ferramentas que serão necessárias para esse fim. Essas ferramentas são evidenciadas quando descritos os processos educacionais que fornecerão a esses indivíduos cidadãos a organização e distribuição de conhecimentos e habilidades disponíveis num certo momento histórico, preparação para o trabalho, acesso ao desenvolvimento tecnológico, participação crítica na vida política.

Todo esse processo possibilita a prática da cidadania demolindo todas as interdições à construção de espaços de liberdade e à ação dos cidadãos. Tais espaços são os locais onde o cidadão ergue o seu modo de ser e de se expressar. Os cidadãos, munidos dos instrumentos da cidadania, tornam-se construtores de formas organizativas e de ação na vida pública. Essa forma de organização social e de ação política denomina-se Democracia.

Logo, a Democracia é o modo como seres humanos autônomos, livres e responsáveis articulam as diversas vontades e capacidades individuais e coletivas para construir um modo de viver que lhes permita o mais alto grau possível de exercício de sua liberdade, em um espaço público.

Em suma a Educação torna-se uma ação intencional colocada externamente sobre um indivíduo que deve ser formado como ser humano pleno, integral. Sendo um ato intencional e externo, ele é desempenhado primeiramente pelos que antecedem na vida social os que estão sendo formados.

Somos desamparados de uma democracia efetiva, submetidos a jogos ideológicos que estabelecem como democracia simplesmente o fato de votar obrigatoriamente, mas que democracia é essa onde não podemos aliar os conceitos de ética e educação como direitos básicos dos indivíduos? A educação de maneira geral, não é construída em moldes éticos e democráticos, com raríssimas exceções, sendo na maioria dos 
casos uma educação para criar seres automatizados e alienados e efetivamente esta é a prova mais veemente da falência dos preceitos que interligam esses valores.

\section{REFERÊNCIAS}

ALBUQUERQUE, Targélia de Souza. Ética e Avaliação: uma discussão necessária para a construção da escola democrática. In: Avaliação da Educação e da Aprendizagem.- Curitiba: IESDE, 2006.

ARENDT, Hannah. Entre o passado e o futuro. São Paulo: Perspectiva, 1978

BROCHADO, Mariah. Ética e as relações entre estado, política e cidadania. Cad. Esc. do Legislativo, Belo Horizonte, vol 12, n 19, p 57-82, julho-dezembro 2010.

CARVALHO, José Sérgio. Podem a ética e a cidadania serem ensinadas? Proposições, v. 13, n. 3, p. 157-168, 2016.

DEWEY,J. Experience and Education. New York ,Free Press, 1997

DUSSEL, Enrique. Ética da Libertação na Idade da Globalização e da Exclusão. Petrópolis: Vozes, 2000.

FREIRE, Paulo. Pedagogia da autonomia: saberes necessários à prática educativa. São Paulo: Paz e Terra, 1996

FREIRE, Paulo.. Educação como prática da liberdade. 19. ed. Rio de Janeiro: Paz e Terra, 2000.

FREIRE, Paulo. Educação como prática da liberdade. 25aㅡ ed. Rio de Janeiro: Paz e Terra, 2001.

FREIRE, Paulo. Pedagogia da esperança: um reencontro com a Pedagogia do oprimido. 9. edição. Rio de Janeiro: Paz e Terra, 2002. 
MELLO, Mário Vieira de. O homem curioso: o problema da exterioridade na filosofia de Aristóteles. Rio de Janeiro: Paz e Terra, 2001.

OLIVEIRA, Ivanilde Apoluceno de. A interação entre os saberes na prática educativa popular: estudo de uma experiência escolar. 1994. 222f. Dissertação (Mestrado em Educação). Universidade Federal da Paraíba, João Pessoa, 1994

SANTOS, Boaventura de Sousa. Um discurso sobre as ciências. 9 ed. Porto: Afrontamento, 1997.

SANTOS, Boaventura de Sousa. A Crítica da Razão Indolente: Contra o Desperdício da Experiência. São Paulo: Cortez, 2000.

SANTOS, Boaventura de Sousa. A universidade no século XXI: para uma reforma democrática e emancipatória da universidade. 2004.

XAVIER, Gabriela Costa; OTONI, Flávia; ESPÍNOLA, Thaísa Ferreira Amaral Gomes. Educação como instrumento de efetivação da democracia. Fórum Administrativo: Direito Público, 2015. 